\title{
Determining piglet survival
}

\author{
Emma M. Baxter ${ }^{1 *} \&$ Sandra A. Edwards ${ }^{2}$ \\ ${ }^{1}$ Animal Behaviour and Welfare, Animal and Veterinary Sciences Research Group, SRUC, \\ Edinburgh, UK ${ }^{2}$ School of Agriculture, Food and Rural Development, University of Newcastle, \\ Newcastle Upon Tyne, UK
}

\begin{abstract}
The sow, piglet and their environment interact together to determine whether or not a piglet will survive to weaning. The physiology of the mother and offspring, as well as the synchronized expression of their appropriate behaviours, is integral to piglet survival and both are governed by genetic and environmental components. This review discusses the multifaceted nature of piglet survival, concentrating on the environmental factors that pre-dispose prenatal (stillborn) and postnatal death and the progress made towards understanding and decreasing piglet mortality.
\end{abstract}

\section{Introduction}

A certain amount of piglet mortality might be considered an inevitable event. A percentage of piglets are expected to die before weaning (10-20\%, Edwards 2002) and may reflect a form of natural selection implemented by the sow whereby only the fittest offspring survive in challenging conditions. The evolutionary strategy adopted by the sow is one of over-producing; a form of parental optimism where production of numerous neonates allows replacement offspring in the event of members of the litter dying (Mock \& Forbes 1995; Forbes \& Mock 1998) and prepares for an unpredictable lactation phase, where resources may be plentiful or sparse. The often disproportionate provision of resources (i.e. milk) to the litter, further results in intense sibling rivalry, likened to avian facultative siblicide (Fraser et al. 1995), and increased mortality. Over-supplying offspring and providing limited resources is evident long before birth; with high ovulation rates but $30-50 \%$ of released ova not surviving gestation in the finite uterine space (Pope 1994; Geisert \& Schmitt 2002).

In a polytocous species, such as the pig, embryo mortality, parental optimism and "siblicide" are considered normal. The limited success of attempts to reduce piglet mortality under domestic conditions may reflect these hard-wired evolutionary strategies. Continued selection pressure for hyper-prolificacy has further increased the challenge of piglet survival. Understanding the causes of mortality and the risk factors that predispose different types of death is crucial to focus solutions on both environmental and biological elements.

\section{What are the main causes of piglet mortality?}

Pre-weaning mortality (PWM) of live-born piglets is, on average, 11.5\% (BPEX 2011), which varies between countries (Figure 1). With the inclusion of those piglets that are born dead (approximately $8 \%$ - Leenhouwers et al. 1999), total mortality averages $16-20 \%$ (Knol et al. 2002a; BPEX 2012).

Attempts to decrease piglet mortality have mainly been directed at the farrowing environment and husbandry procedures. The farrowing crate was introduced in the 1960s (Robertson et al. 1966) to decrease piglet over-lays by restricting sow movements, and to improve ease of 


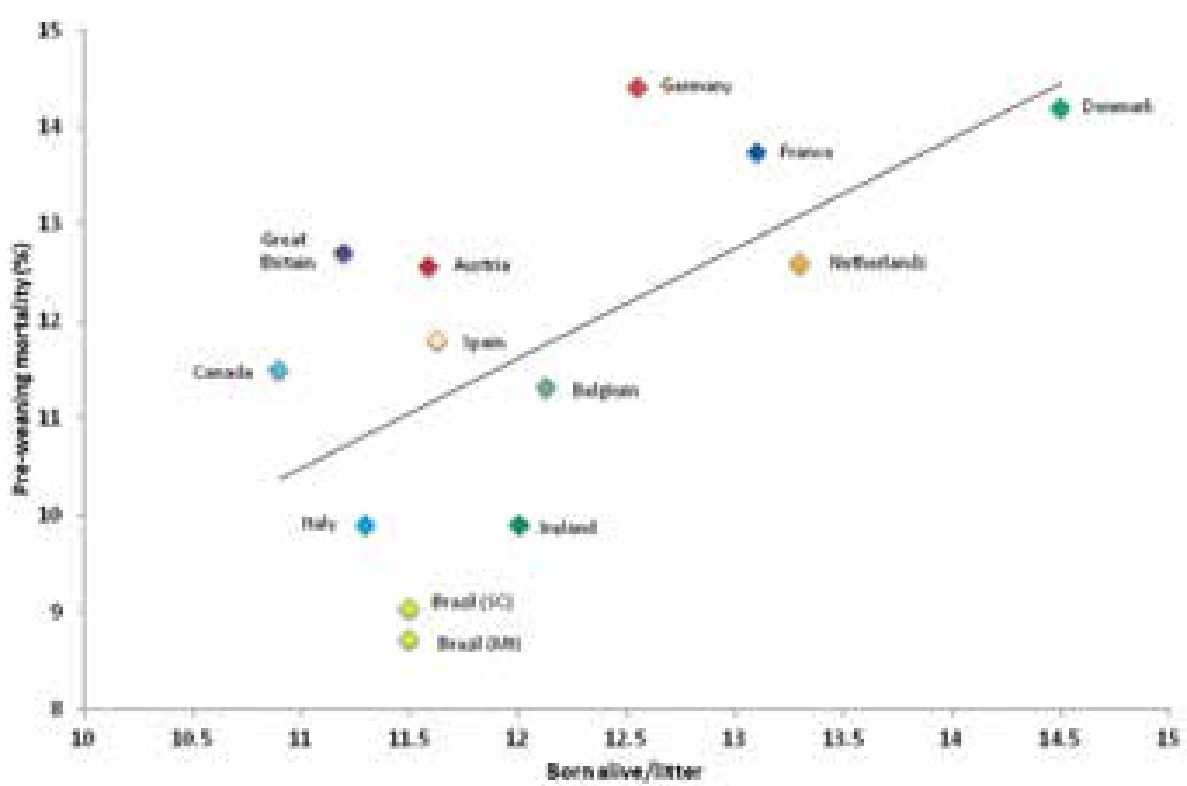

Fig. 1 Relationship between numbers born alive and pre-weaning mortality (percentage of piglets that are born alive but die pre-weaning) for selected countries in the European Union, Canada and Brazil. Source - Interpig 2010 (BPEX 2011).

management (Edwards \& Fraser 1997). However, despite efforts to better understand and reduce piglet mortality, average losses have not changed significantly in recent years and, lately, there is a trend for increases (Rutherford et al. 2013), most likely as a result of increased prolificacy (Figure 1). There have been a number of comprehensive reviews articles relating to piglet mortality (English \& Smith 1975; Dyck \& Swierstra 1987; Edwards et al. 1994; English \& Edwards 1996; Marchant et al. 2000; Edwards 2002; Lay et al. 2002; Mellor \& Stafford 2004), with a great deal of consistency regarding the main causes of death and implicating the first 72 hours of life as the critical period for survival. Dyck and Swierstra (1987) identified eight specific causes of death, but the main three are stillbirths, crushing by the sow and starvation.

\section{What pre-disposes stillborn mortality?}

The prenatal period includes the period before farrowing and the parturition process itself. Mortality in utero during the embryo elongation phase can be followed by post implantation losses in crowded uterine conditions (Foxcroft et al. 2006). For the fetuses that survive to full term, there remain risks that can lead to stillbirth. There are two main types of stillbirth; type 1 includes the fully or partly mummified piglets that have died pre-partum and are generally attributed to intrauterine infection (Alonso-Spilsbury et al. 2005) as well as intrauterine crowding (Vallet et al. 2002). Type 2 stillbirths are more common, with non-infectious aetiologies (summarised in Figure 2). The major influencing factors are prolonged duration of farrowing, delivery in the last third of the birth order, premature rupture of the umbilical cord, sow behavioural and physiological characteristics, including parity and blood haemoglobin concentration of less than $9 \mathrm{~g} / 100 \mathrm{ml}$ (Randall 1972a,b; Fahmy \& Friend 1981; Zaleski \& Hacker 1993; van Rens \& van der Lende 2004; van Djik et al. 2005; Baxter et al. 2008). These factors often result in asphyxiation (van der Lende et al. 2001; Alonso-Spilsbury et al. 2005; 


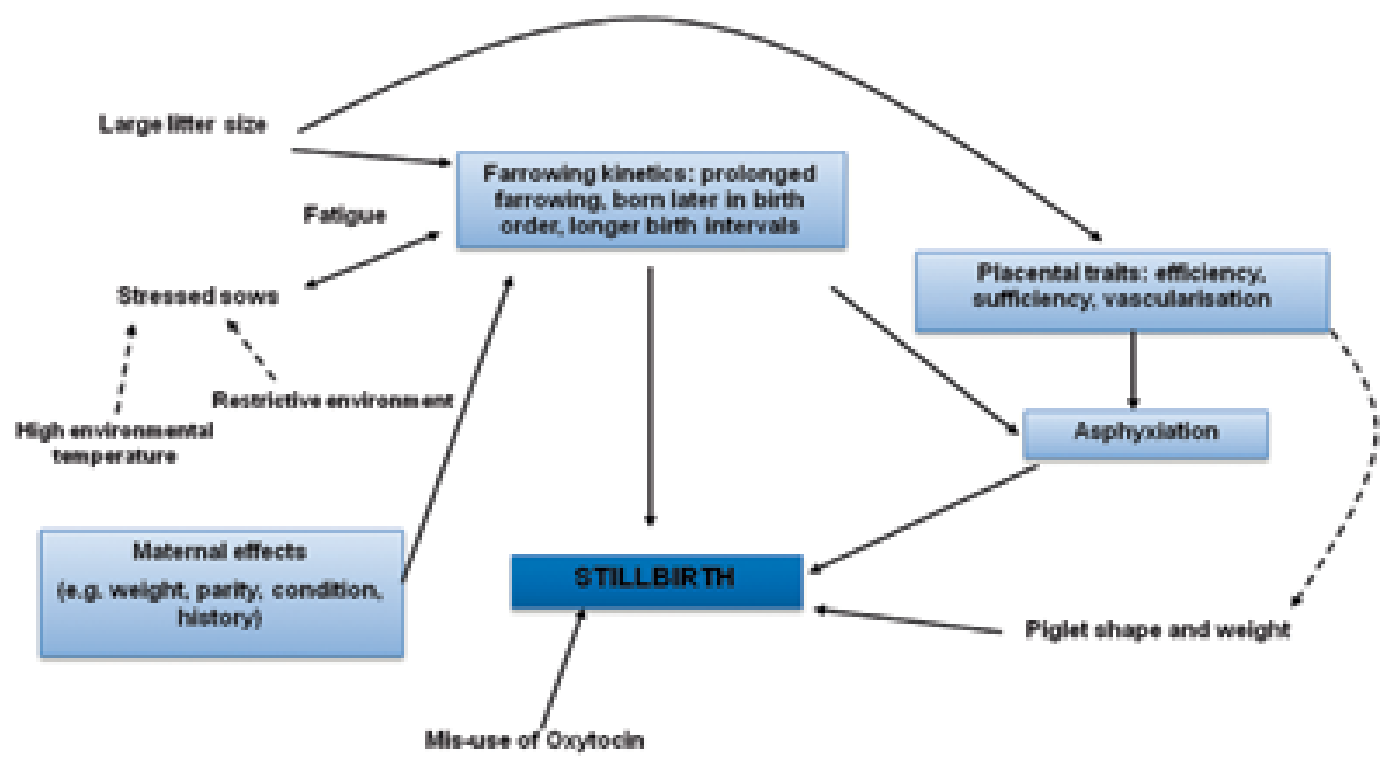

Fig. 2 Pre-disposing events of still-born mortality

Mota-Rojas et al. 2005; van Dijk et al. 2008), or a less viable piglet with poor survival chances post-partum. The predisposing factors are not independent, for example prolonged farrowing duration is influenced by increased litter size (van Rens \& van der Lende 2004; Andersen et al. 2011), sow stress associated with fatigue (van Kempen 2007; Vallet et al. 2010), restrictive farrowing environments (Oliverio et al. 2006) and high ambient temperatures (Vanderhaeghe et al. 2010).

The pharmacological induction of parturition, to synchronise and supervise farrowings and therefore reduce PWM (Černe \& Jöchle 1981), can be counter-productive because of increased birthing complications and stillbirths (Mota-Rojas et al. 2002). The timing of induction is critical, since late fetal development and maturation is a predisposing factor in survival (Randall 1972b; van der Lende et al. 2001) and the general consensus is not to induce before d113 of gestation (see Kirkden et al. 2013 for review) and not in gilts as service dates are rarely accurate. In the days preceding farrowing, the fetus experiences an increase in growth rate (Biensen et al. 1998) and development, with final physiological preparations for extra-uterine life, particularly lung maturation. Premature induction of birth may therefore result in a compromised neonate. Oxytocin administration, designed to aid farrowing progress in situations of fatigue, can increase fetal asphyxia by increasing the uterine muscle contractions, impeding gaseous exchange between mother and fetus and increasing the chances of umbilical occlusion (Alonso-Splisbury et al. 2004, 2005; Mota-Rojas et al. 2002, 2006). Administration of oxytocin in these studies resulted in increased piglet bradycardia and meconium staining, with severe acidosis and compromised survival. Thus the mis-use of drugs designed to improve farrowing outcomes is an important risk factor in stillborn mortality.

\section{Maternal condition - genotype, nutrition, parity and history}

The mother plays a crucial role in fetal survival during the gestation phase, mediated through uterine space and placental quality. Van Dijk et al. (2005) reported breed effects on stillborn 
mortality and found that an increased duration of expulsion was significantly associated with increased litter size, increased number of stillborns per litter and decreased length of gestation (independent of litter size).

Feeding during gestation requires a fine balance, with both under- and over-nutrition affecting many developmental processes. Over-feeding of the sow during the last third of pregnancy can indirectly compromise piglets by affecting the mother's farrowing ability; if piglets become too big, the inter-birth interval will increase, as will the potential for umbilical cord occlusion and stillbirth (Leenhouwers et al. 2001). The immediate impact on the fetus if the sow is under-fed during gestation involves negative effects on placental size, fetal growth and the deposition of fetal fat reserves for use after birth (Wu et al. 2004). Malnutrition in gestation can lead to impaired mammary gland development (Head \& Williams 1992; Kim et al. 1999), poor lactational output and may affect the future reproductive capabilities of the offspring (Kerr \& Cameron 1995; O'Dowd et al. 1997). There are even considered to be intergenerational influences (Gluckman \& Hanson 2004), as maternal metabolic function may itself have been programmed when the mother was a fetus.

Young sows of lean-genotype are more likely to suffer excessive depletion of body protein reserves during lactation which will affect neonatal growth rates, as well as the subsequent, developing litter (Edwards 1998). Sows of advanced parity give birth to a higher incidence of stillborn piglets (Randall \& Penny 1970; Leenhouwers et al. 2003) and farmers report that sows giving birth to dead piglets often consistently produce stillborn piglets in subsequent litters, thus highlighting a genetic component to this trait (Roehe et al. 2010).

\section{Placental traits and piglet growth characteristics}

Suidae have a non-invasive epitheliochorial placentation, which is considered to be relatively inefficient and diffuse. Placental efficiency (birth weight/placental weight (PE)) was studied in Meishans (Wilson et al. 1998) which are able to support a greater litter size to term than their occidental counterparts (Large White, Yorkshire, Landrace - Lee et al. 1995). Wilson et al. (1998) reported that this was due to the decreased pre-implantation growth rate and oestrogen biosynthetic activity of the Meishan conceptus compared with occidental breeds, which allowed more conceptuses to survive beyond day 18 of gestation. Furthermore, it is hypothesised that Meishan conceptuses are smaller and remain small throughout gestation, and that their placentas are smaller and more efficient. Both large and small fetuses can develop on either a small or large placenta, with more efficient placentas being generally smaller and more vascularised.

Placental insufficiency can result in a chain of events that will compromise fetal and neonatal survival. It is a major cause of intrauterine growth restriction/retardation (IUGR) and, since piglet birth weight is often heralded as the most important survival indicator (e.g. Kerr \& Cameron 1995; Roehe \& Kalm 2000), such prenatal insults can result in a stillborn piglet or a live-born piglet with low viability and compromised survival. Recently the importance of birth weight per se with regard to prenatal survival has been questioned; Baxter et al. (2008) found that stillborn piglets were disproportionately long and thin, with lower ponderal index (PI) and body mass index (BMI) (indicative of IUGR) compared with surviving littermates, and found that PI and BMI were more predictive of whether or not a piglet would be stillborn than birth weight alone. These results have since been replicated (Pedersen et al. 2011a; Rootwelt et al. 2012). The quadratic relationship between birth weight and stillborn mortality (Canario et al. 2006) shows that, at least for prenatal survival, birth weight is not a simple predictor of stillbirth. Very small piglets and "giant" piglets are equally at risk, with heavier piglets often being more hypoxic than lighter littermates as a result of birthing difficulties (Trujillo-Ortega et al. 2007).

Baxter et al. (2008) associated their gross measure of IUGR (i.e. BMI and PI) with lower total placental areolae number and areolae density, placental traits key in the transfer of nutrients, 
particularly protein, between mother and fetus. They found a further relationship between areolae traits and piglet vitality at birth, and Rootwelt et al. (2012) also associated placental area with piglet vitality, thus emphasising the influence of placental quality on postnatal viability.

\section{What predisposes live-born mortality?}

Survival of the newborn piglet depends on its ability to overcome the physiological challenges associated with the extra-uterine environment. These include behavioural and physiological adaptations such as the ability to adequately thermoregulate, the ability to find and defend a functional teat, suckle and absorb vital nutrients from the mother's colostrum as well as respond to maternal cues. The multifactorial nature of live-born piglet mortality is summarised in Figure 3.

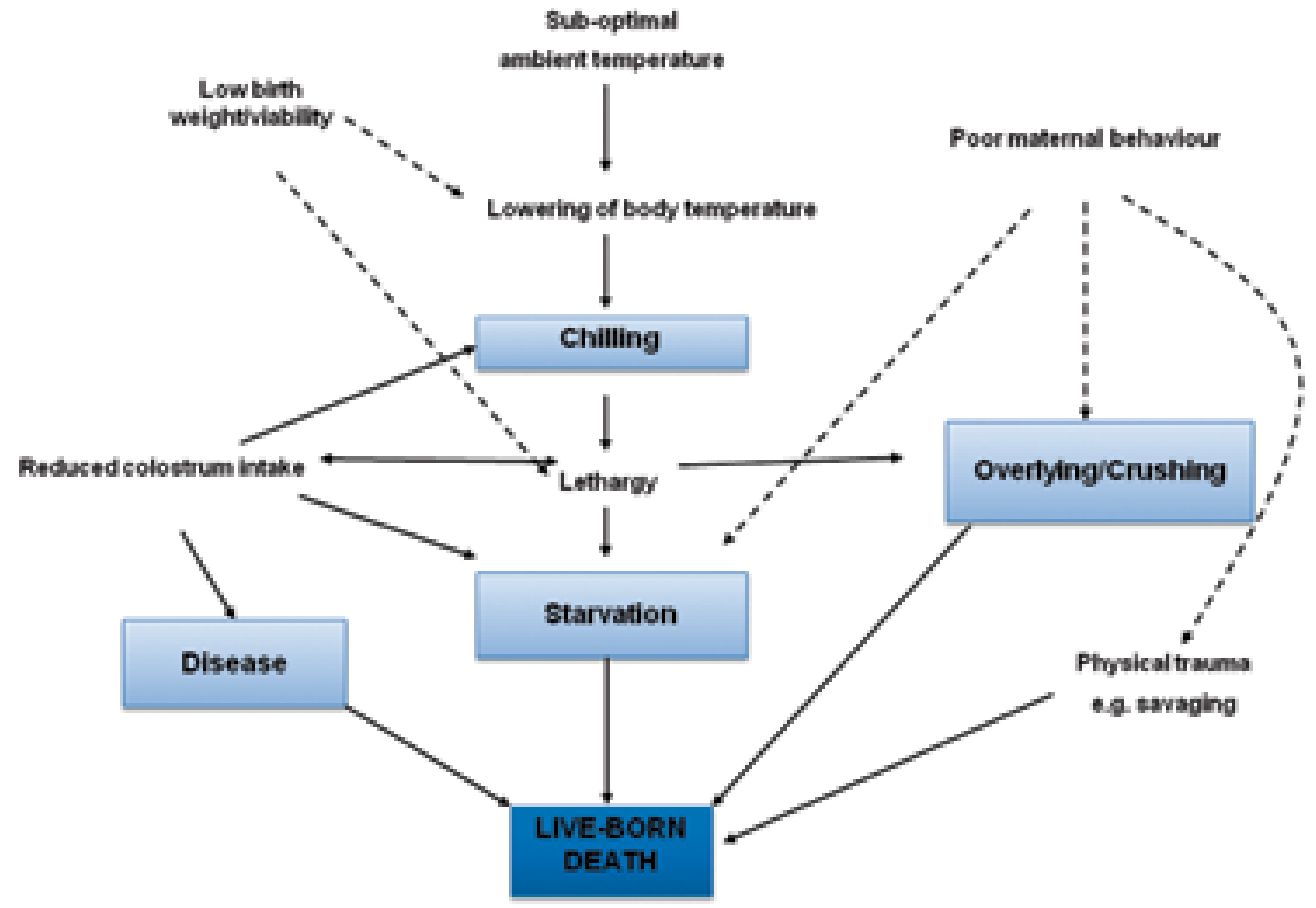

Fig 3. Pre-disposing events of live-born mortality and the interactive events occurring in the chilling-starvation-overlying-disease complex. Adapted from Edwards 2002

\section{Chilling/Hypothermia}

Hypothermia is considered, directly or indirectly, to be responsible for more deaths than crushing, starvation, disease or low viability (Curtis 1970). However, without continuous monitoring of rectal temperatures it cannot be determined, and thus the most easily discernible cause of death, crushing by the sow, is often over recorded (Vaillancourt et al. 1990; Christensen \& Svensmark 1997).

From the moment the piglet is born it suffers from a reduction of ambient temperature (approximately a $15-20^{\circ} \mathrm{C}$ drop - Curtis 1970; Herpin et al. 2002), such that its lower critical temperature (approximately $34^{\circ} \mathrm{C}$ - Mount 1968), is not achieved. The newborn piglet therefore rapidly loses heat via different processes (reviewed by Curtis 1970). These heat loss processes are affected by physical, behavioural and environmental factors. The size of the piglet affects 
the rate of heat loss, with smaller piglets having a proportionally larger surface area from which heat is transferred via convection (Curtis 1970; Herpin et al. 2002). Higher air velocity and a larger temperature gradient will also increase convective heat loss (Mount 1964). Early work on conductive heat loss (Mount 1967; reviewed by Curtis 1970) showed that piglets in contact with a concrete floor lost $40 \%$ more heat than those in contact with bedding material (i.e. 2.5 $\mathrm{cm}$ straw). Investigations in "natural" farrowing conditions show that nests are robust to climatic extremes as a result of reduction in losses by conduction, convection and radiation (Algers \& Jensen 1990; Baxter et al. 2009). Radiative heat loss is affected by the temperature gradient, the surface area of the surrounding surfaces and the distance between the piglet and these surfaces, and will not be over-come by increasing ambient temperature. Finally, evaporative heat loss is particularly problematic, because it drains energy to dissipate placental fluids as water vapour. All piglets will experience this rapid cooling since the sow will not remove placental membranes by licking, as do other livestock species. Again, low birth weight will increase relative evaporation losses via the increased relative surface area, as will increased air velocity (e.g. drafts from ventilation systems - Curtis 1972) and low ambient air pressure. Once the placental fluids have evaporated or been physically removed by stockperson intervention or friction with other piglets or bedding material, evaporative heat loss is still experienced from mucosal surfaces via respiration.

The metabolic capability of the neonate affects the extent to which heat loss associated with the extra-uterine temperature drop impacts upon the piglet. If environmental conditions are inadequate to prevent the ambient temperature dropping below $34^{\circ} \mathrm{C}$, then secondary defences are deployed via an increase in metabolic rate and shivering thermogenesis. Both these process are likely, given that heating the environment to $34^{\circ} \mathrm{C}$ would impact on the sow's thermal comfort zone (Mount 1968), which ranges from $12-22^{\circ} \mathrm{C}$ (Black et al. 1993), and thus is markedly different from that of the newborn piglet. Initiation and sustainability of the thermogenic response to cold (i.e. a continuing increase in metabolic rate) is dependent on intake and metabolism of colostrum (Herpin et al. 1994). However, other factors also contribute, directly or indirectly, to hypothermia risk. If a fetus has a suboptimal placenta this will cause chronic fetal hypoxaemia (Rees et al. 1998). The observed elevated lactate is associated with anaerobic metabolism and a decreased haematocrit reflects the decreased percentage of red blood cells in the plasma resulting from the reduced oxygen supply. Acute asphyxia at birth may also cause metabolic acidosis, hyperlactaemia, hypoxia and meconium aspiration syndrome (Herpin et al. 1996; Alonso-Spilsbury et al. 2005). Herpin et al. (1996) found a relationship between asphyxia at birth and reduced neonatal vitality; piglets were slower to reach the udder and had a lower rectal temperature 24 hours after birth, as well as reduced growth rate and survival over the first 10 days post-partum. Restriction of the oxygen supply during fetal development has possible consequences for central nervous system (CNS) function. Damage to the fetal CNS can impair sucking and locomotor activities in pigs (Herpin et al. 1996) and impairs thermoregulation in the neonate (Stanton et al. 1973).

The typical, domestic piglet is born with very little adipose tissue, no brown fat (Herpin et al. 2002) and little pelage with which to assist thermoregulation. It must take in colostrum as soon as possible to prevent catabolism of its skeletal muscle to fuel heat production. Thermoregulation requires the co-ordinated maturation of various organs and functions that were unnecessary for survival in utero (Herpin \& Le Dividich 1995). If a piglet is unable to produce heat, it may be a result of an immature thermogenic mechanism arising from, for example, premature birth and/or reduced thyroidal and adrenocorticol support for postnatal metabolic activity (Mellor and Stafford 2004). Intensive genetic selection for lean tissue growth rate has resulted in piglets with reduced physiological maturity for their size at birth, and thus poor thermoregulatory abilities (Herpin et al. 1993). 
Starvation occurs when a piglet fails to ingest or metabolise colostrum, and subsequently milk, from the sow. Post-mortem analysis of dead piglets, presumed crushed, often shows the stomach to be empty, indicating that starvation is part of the mortality complex involving hypothermia and crushing (Edwards 2002; Pedersen et al. 2011b). Colostrum is important for both energy balance and immune protection (see later section). Lactational output of the sow is not the only factor determining how much milk the piglets receive. Piglets will fight to gain teat access and to maintain teat fidelity and, if they are unable to perform optimal udder massaging and suckling behaviours, teat function may be impaired. Piglets failing to establish teat fidelity grow more slowly (De Passillé et al. 1988) and get-by on opportunistic suckling or often starve. De Passillé and Rushen (1989) found that heavier piglets, born earlier in the birth order, won more teat disputes, established teat fidelity quicker, suckled more frequently and ultimately were at a distinct advantage over less vigourous littermates. However piglet vigour is not necessarily correlated with weight; using a sophisticated measure of vigour based on the strength and persistence with which the newborn piglet manipulated an artificial teat linked to a computer registration system, Baxter et al (2008) demonstrated that a small yet vigourous piglet could survive equally well as its larger conspecifics. However, even if a piglet possesses such vigour, a large litter size, where piglets outnumber functional teats, will require managerial intervention to prevent starvation (Baxter et al. 2013). Sow physiology and behaviour will also influence the efficiency with which piglets suckle a functional teat; reduced lactational output, poor teat quality (Fraser and Lin 1984) and poor maternal behaviour (Andersen et al. 2005) and udder exposure (Pedersen et al. 2011c) will impact negatively on the nutritional status of the piglet.

\section{Crushing}

Crushing is thought to account for the majority of neonatal deaths and, given its importance, is a well-researched area of the hypothermia-starvation-crushing complex. There is a trade-off between the innate need of the piglet to be at the warm udder, gaining valuable colostrum and establishing teat fidelity, against the risk of being crushed by the sow. Weary et al. (1996) concluded that crushings are partly the result of the nutritional challenge facing piglets; a piglet with slow weight gain spent more time in risky areas underneath its sitting or standing mother. If the piglet's energy reserves are low, it will also be too weak to escape a moving sow. Sow behaviours influencing crushing risk include lack of piglet directed pre-lying behaviour, the frequency and nature of posture changes and failure to rise in response to a trapped piglet (Marchant et al. 2001; Thodberg et al. 2002; Andersen et al. 2005). The latter aspect will be affected by the sow's condition, which may be linked with parity, as well as her inherent responsiveness and her farrowing environment. Older parity sows may experience increased leg weakness impeding posture changes (Damm et al. 2005; Pedersen et al. 2006), whilst the enforced restraint of a farrowing crate will limit the effectiveness of response to a crushed piglet.

The farrowing environment, to a certain extent, dictates the interaction between mother and young. In a loose-housed system, piglet-directed pre-lying behaviour is associated with good maternal ability. Sows will paw the ground or substrate, or make nose-to-piglet contact before lying down (Wechsler \& Weber 2007). In choice experiments (Herskin et al. 1998), provision of bedding and substrate improved maternal behaviour by reducing the number of posture changes and therefore reduced crushing risk.

The sow's temperament is also influential (Marchant et al. 2001). There is individual variation regarding maternal ability and sows who are deemed "crushers" behave differently to "noncrushers" (Andersen et al. 2005; Jarvis et al. 2005). The consistency of behavioural patterns within individuals, and the high variation within populations, suggests a possibility of selecting 
for "non-crushers" (Grandison et al. 2003). The piglet's behaviour that influence crushing often occur as a result of physiological challenges such as hypoxia, starvation or hypothermia, which may increase lethargy. Since reduction of heat loss at birth is mainly achieved by behavioural adjustments, including huddling and postural adaptations (Hrupka et al. 2000), where a piglet chooses to lie in the nest site may be crucial for its survival. For a piglet with low viability, facing demanding physiological challenges, it will be just as dangerous to lie away from the udder and siblings, since although the risk of crushing is reduced; the risks of starvation and hypothermia become much greater.

\section{Disease, infection and injury}

Neonatal diseases result from the interaction of a multitude of factors (Martineau et al. 1995). The epitheliochorial nature of the porcine placenta means that the newborn piglet must acquire maternal immunoglobulins from ingesting colostrum for passive immune protection (Rooke \& Bland 2002). The immune system of the piglet itself does not become fully developed until at least weaning (Gaskins \& Kelly 1995). Failure to ingest sufficient colostrum soon after birth results in sub-optimal transfer of maternal immunoglobulins to the neonate, and increased susceptibility to disease (Gaskin \& Kelly 1995; Rooke \& Bland 2002). It has been suggested that colostrum intake below $200 \mathrm{~g}$ per piglet in the first 24 hours of life is a significant risk factor for piglet mortality (Devillers et al 2011). Issues to do with piglet colostrum intake have been thoroughly reviewed by Quesnel and colleagues (2012).

The physiological maturity of the newborn will affect its ability to maintain health and survive. Immature organ development will impact upon the piglet's ability to process any milk it obtains and there is a finite amount of time before gut closure commences (approximately $48 \mathrm{~h}$ ) when it is important for the piglet to obtain and process colostrum (Cranwell 1995). Getting to the udder, commanding a functional teat and suckling colostrum quickly not only aids thermoregulation and the acquisition of immunoglobulins and nutrients, but also aids gut closure. There are two major windows of opportunity for pathogens to enter the piglet's systemic circulation. The first is within the first $24 \mathrm{~h}$ of life and is influenced by delayed colostrum intake which can cause subsequent delay in gut closure. The second opportunity is between the time of declining antibody levels in the sow's milk and the transition from passive to active immunity in the piglet (Gaskins \& Kelley 1995). Poor management practice with regard to hygiene and disease treatment will be major determinants of the risk of neonatal diseases and infections becoming fatal. Injuries may be acquired by the piglets as a result of over-lying or savaging by the mother and, if they are not immediately fatal, they may result in infection and a later death. It is also possible for piglets to sustain wounds from their siblings and/or abrasive floor surfaces during the competitive scrambling for the teat at milk let-down (Fraser 1975; Mouttotou \& Green 1999; Drake et al 2008).

\section{The influence of farrowing system}

The farrowing system influences the prevalence of certain types of mortality. Riart et al. (2000) conducted post-mortem analysis in indoor and outdoor systems and found crushing to account for approximately $20 \%$ of total mortality in the indoor, crated system and $45 \%$ in the outdoor system. Starvation accounted for approximately $15 \%$ indoors and less than $10 \%$ outdoors. It is often reported that crushing is more prevalent in loose-housed or outdoor systems (alternative systems) where the sow is free to move about during farrowing and lactation, compared with the conventional system where the sow is confined in a crate (Marchant et al. 2000). However, this does not always equate to higher total mortality in these alternative systems and our recent 
review comparing performance suggests that mortality rates can be relatively similar in both conventional and well designed alternative systems (Baxter et al. 2012a).

Higher levels of mis-mothering (e.g. savaging) are reported (Lawrence et al. 1994) when sows are confined in crates whereas this behaviour is rarely seen in alternative systems. Lawrence et al. (1994) found elevated cortisol levels in crated sows and hypothesised this was a consequence of the inability to perform natural behaviours and a likely factor contributing to increased savaging in restrictive environments (Lawrence et al. 1994; McLean et al. 1998; Jarvis et al. 1998; Jarvis et al. 2004).

\section{The influence of piglet gender}

There is evidence that female piglets have a greater chance of surviving from birth to weaning than males (Lay et al. 2002; Baxter et al. 2012b). Baxter et al. (2012b) demonstrated that, despite being born heavier than females, male piglets could not sustain this advantage and showed impaired thermoregulation compared to females, with significantly lower rectal temperatures at $24 \mathrm{~h}$ old. Moreover, piglets from male-biased litters showed reduced thermoregulatory abilities, were slower to suckle colostrum and were more likely to die from disease-related causes. These results suggest male-biased mortality, reflecting an intrinsic, size-related susceptibility to causal factors. This may be masked when competition for resources favours the larger, more dominant individuals but, where individual resources are sparse the effects may be more visible.

\section{The influence of birth weight and litter size}

Throughout the review the importance of birth weight and the disadvantages of large litter size have been alluded to, though they are very difficult to discuss separately, as they are not mutually exclusive. Roehe and Kalm (2000) reported $40 \%$ pre-weaning mortality in pigs with a birth weight of lower than $1 \mathrm{~kg}, 15 \%$ between $1-1.2 \mathrm{~kg}$ and only $7 \%$ when birth weight was above $1.6 \mathrm{~kg}$. Within-litter birth weight variation is potentially more important than individual birth weight. High neonatal-weight variation generally results in lower survival and more variable weaning weights (Roehe 1999; Milligan et al. 2002; Quiniou et al. 2002). This is not an area new to the consideration of piglet survival (English \& Smith 1975), yet is still one to effectively be addressed.

In the course of domestication, selective breeding has delivered more than $100 \%$ increase in litter size. However, the associated mortality levels are becoming unacceptably high with negative effects on other survival and production traits. Quiniou et al. (2002) have shown that increasing litter size from $\leq 11$ to $\geq 16$ resulted in a reduction of mean birth weight from 1.59 $\mathrm{Kg}$ to $1.26 \mathrm{Kg}$, corresponding to a mean decrease of $35 \mathrm{~g}$ for each extra piglet born. Recent reviews by Rutherford et al. (2013) and Baxter et al. (2013) have discussed the biological and managerial challenges of hyper-prolificacy, which will therefore not be in covered in this review. However, it is clear that improving piglet survival remains a significant challenge with increased selection pressure for prolificacy.

\section{Solutions - How can we improve piglet survival?}

A viable piglet is one that will adapt to the extra-uterine environment and survive the pre-weaning period. There are certain aspects of the piglet's behaviour and physiology which potentially aid this task. These include an optimum birth weight, favourable litter size, physiologically mature organ functions maintaining homeostasis and the ability to behaviourally adapt to obtain vital nutrients from the sow. Augmentation of existing environmental solutions and nutritional 
programmes, as well as progression in genetic selection strategies which incorporate survivability within breeding goals, are possible ways of tackling piglet mortality.

\section{Environmental and nutritional factors}

Previous research to reduce piglet mortality was centred almost entirely around alterations to the farrowing environment. Supervision at the time of parturition (Holyoake et al. 1995; Andersen et al. 2009), increased control over the macro- and microclimate and nest area (Schmid 1994) and, of course, the introduction of the farrowing crate (Robertson et al. 1966) are some examples of tools put in place to improve survival. The various accommodation systems for farrowing and lactation and the welfare issues surrounding them have already been reviewed (Edwards \& Fraser 1997; Barnett et al. 2001; Wechsler \& Weber 2007; Baxter et al. 2012a). Adjustments to farrowing systems should consider solutions that optimise both sow and piglet welfare.

Nutritional interventions to improve embryo quality and subsequent birth weight and uniformity have included use of fermentable ingredients in sow diets prior to breeding (Van den Brand et al. 2009), and essential fatty acid supplementation in late gestation to increase piglet vitality (Rooke et al. 2001). Campos et al. (2012) offers a recent review on these offspring benefits, whilst Meunier-Salaün et al. (2001) and de Leeuw et al. (2008) discuss the influence of nutritional interventions on sow welfare.

To ensure that all piglets ingest vital colostrum soon after birth, targeted inputs by stockpeople can assist landmark behaviours (i.e. improve latency to reach the udder and suck colostrum). This is of particular importance when litter size exceeds functional teat number and when a greater number of low vitality, growth-retarded piglets require intervention (see Baxter et al. 2013 for managerial strategies). Improving maternal behaviour and farrowing progression by reducing stress in the periparturient sow can also indirectly assist the piglet. Farrowing duration, and risk of hypoxia, may be reduced by ensuring appropriate sow condition, minimising heat stress and providing enrichment to allow nest-building behaviour and reduce frustration (Thodberg et al. 1999; Jarvis et al. 2001, 2002; Damm et al. 2003, 2005). Providing substrate will not only facilitate improved maternal behaviour (Herskin et al. 1998) but will provide a microclimate for newborn piglets.

\section{Selection for improved survival}

Adjusting selection criteria to include neonatal survival, in addition to number born, is a more sustainable strategy and one that has achieved success in improving piglet survival rates (Roehe et al., 2009, 2010). The Danish pig industry, renowned for its success in increasing litter size, has recognized the accompanying significant increase in mortality which occurred (5\% increase in total pre-weaning mortality). In 2004 it changed its selection criterion from total born to 'live piglets at day 5' (LP5) (Su et al. 2007) and, although mortality is still high, this has been stabilised with the net result of an increase of 2.3 pigs weaned/litter. This may reflect successful management of the surplus piglets, or indicate that selecting for survival may not result in as many compromised piglets (e.g. pathologically growth retarded) as selecting for number born. Reducing intra-litter variability, particularly with respect to birth weight, is an additional important breeding goal discussed by numerous authors (Rydhmer 2000; Knol et al. 2002a,b; Damgaard et al. 2003; Huby et al. 2003). Selecting for improved placental efficiency is another potential strategy to improve piglet outcomes (van Rens et al. 2005). Furthermore, breeding for improved maternal behaviour (Grandison 2005; Gade et al. 2007; Baxter et al. 2011) and investigating strategies for breeding a more robust piglet both have potential to reduce mortality. 


\section{Conclusions}

Piglet mortality is multifaceted in nature and, as a result, finding solutions requires addressing all aspects of the problem. Little progress has been made over the last two decades in reducing piglet mortality. Nutritional interventions for the sow during gestation and lactation have scope to enhance piglet outcomes. Postnatal managerial interventions to assist vulnerable neonates must continue to be a focus for stockpeople, particularly as prolificacy increases. Coupling these environmental and nutritional interventions with a balanced selection programme offers the best chances of success in improving piglet survival.

\section{References}

Algers B \& Jensen P 1990. Thermal microclimate in winter farrowing nests of free-ranging domestic pigs. Livestock Production Science 25 177-181.

Alonso-Spilsbury M, Mota-Rojas D, Martinez-Burnes J, Arch E, Lopez Mayagoitia A, Ramirez-Necoechea R, Olmos A \& Trujillo ME 2004. Use of oxytocin in penned sows and its effect on fetal intra-partum asphyxia. Animal Reproduction Science 84 157-167.

Alonso-Spilsbury M, Mota-Rojas D, Villanueva-Garcia D, Martinez-Burnes J, Orozco H, Ramirez-Necoechea R, Mayagoitia AL \& Trujillo ME 2005. Perinatal asphyxia pathophysiology in pig and human: A review. Animal Reproduction Science 90 1-30.

Andersen IL, Naevdal E \& Bøe KE 2011. Maternal investment, sibling competition, and offspring survival with increasing litter size and parity in pigs (Sus scrofa). Behavioral Ecology and Sociobiology 65 1159-1167

Andersen IL, Haukvik IA \& Bøe KE 2009. Drying and warming immediately after birth may reduce piglet mortality in loose-housed sows. Animal 3 592-597.

Andersen IL, Berg S \& Bøe KE 2005. Crushing of piglets by the mother sow (Sus scrofa)--purely accidental or a poor mother? Applied Animal Behaviour Science 93 229-243.

Barnett JL, Hemsworth PH, Cronin GM, Jongman EC \& Hutson GD 2001. A review of the welfare issues for sows and piglets in relation to housing. Australian Journal of Agricultural Research 52 1-28.

Baxter EM, Rutherford KMD, D'Eath RB, Arnott G, Turner SP, Sandøe P, Mousten VA, Thorup F, Edwards SA \& Lawrence AB 2013. The welfare implications of large litter size in the domestic pig II: Management factors. Animal Welfare 22 219-238. doi: 10.7120/09627286.22.2.219.

Baxter EM, Lawrence AB \& Edwards SA 2012a. Alternative farrowing accommodation: welfare and economic aspects of existing farrowing and lactation systems for pigs. Animal 6 96-117.

Baxter EM, Jarvis S, Palarea-Albaladejo J \& Edwards SA 2012b. The Weaker Sex? The Propensity for MaleBiased Piglet Mortality. PLoS ONE 7 e30318.

Baxter EM, Jarvis S, Sherwood L, Farish M, Roehe R, Lawrence AB \& Edwards SA 2011 Genetic and environmental effects of piglet survival and maternal behaviour of the farrowing sow. Applied Animal Behaviour Science 130 28-41.
Baxter EM, Jarvis S, Sherwood L, Robson SK, Ormandy E, Farish M, Smurthwaite KM, Roehe R, Lawrence AB \& Edwards SA 2009 Indicators of piglet survival in an outdoor farrowing system. Livestock Science 124 266-276.

Baxter EM, Jarvis S, D'Eath RB, Ross DW, Nevison IM, Robson SK, Farish M, Lawrence AB \& Edwards SA 2008 Investigating the behavioural and physiological indicators of neonatal survival in pigs. Theriogenology $69773-783$.

Biensen NJ, Wilson ME \& Ford SP 1998 The impact of either a Meishan or Yorkshire uterus on Meishan or Yorkshire fetal and placental development to days 70, 90, and 110 of gestation. Journal of Animal Science 76 2169-2176.

Black JL, Mullan BP, Lorschy ML \& Giles LR 1993 Lactation in the sow during heat stress. Livestock Production Science 35 153-170.

BPEX 20112010 Pig cost of production in selected countries. BPEX, Agriculture and Horticulture Development Board (AHDB), Stoneleigh, UK.

BPEX 2012 The Pig Yearbook 2012. BPEX, Agriculture and Horticulture Development Board (AHDB), Stoneleigh, UK.

Campos PHRF, Silva BAN, Donzele JL, Oliveira RFM \& Knol EF 2012 Effects of sow nutrition during gestation on within-litter birth weight variation: a review. Animal 6 797-806.

Canario L, Cantoni E, Le Bihan E, Caritez JC, Billon Y, Bidanel JP \& Foulley JL 2006 Between-breed variability of stillbirth and its relationship with sow and piglet characteristics. Journal of Animal Science 84 3185-3196.

Cerne F \& Jochle W 1981 Clinical evaluations of a new prostaglandin analog in pigs: 1 . Control of parturition and of the MMA-syndrome. Theriogenology 16 459467.

Christensen J \& Svensmark B 1997 Evaluation of producer-recorded causes of preweaning mortality in Danish sow herds. Preventive Veterinary Medicine 32 155-164.

Cranwell PD 1995. Development of the neonatal gut. In: The Neonatal Pig: Development and Survival (Ed. by M.A.Varley), pp. 99-154. CAB International, Wallingford, UK. 
Curtis SE 1970 Environmental-thermoregulatory interactions and neonatal piglet survival. Journal of Animal Science 31 576-587.

Curtis SE 1972 Air environment and animal performance. Journal of Animal Science 35 628-634.

Damgaard LH, Rydhmer L, Lovendahl P \& Grandinson K 2003 Genetic parameters for within-litter variation in piglet birth weight and change in within-litter variation during suckling. Journal of Animal Science 81 604-610.

Damm BI, Pedersen LJ, Heiskanen T \& Nielsen NP 2005 Long-stemmed straw as an additional nesting material in modified Schmid pens in a commercial breeding unit: effects on sow behaviour, and on piglet mortality and growth. Applied Animal Behaviour Science 92 45-60.

Damm BI, Pedersen LJ, Marchant-Forde JN \& Gilbert CL 2003 Does feed-back from a nest affect periparturient behaviour, heart rate and circulatory cortisol and oxytocin in gilts? Applied Animal Behaviour Science 83 55-76.

De Leeuw JA, Bolhuis JE, Bosch G \& Gerrits WJJ 2008 Effects of dietary fibre on behaviour and satiety in pigs. Proceedings of the Nutritional Society 67 334-342.

De Passillé AMB \& Rushen J 1989 Suckling and teat disputes by neonatal piglets. Applied Animal Behaviour Science 22 23-38.

De Passillé AMB, Rushen J \& Harstock TG 1988 Ontogeny of teat fidelity in pigs and its relation to competition at suckling. Canadian Journal of Animal Science 68 325-338.

Devillers N, LeDividich J \& Prunier A 2011 Influence of colostrum intake on piglet survival and immunity. Animal 5 1605-1612.

Drake A, Fraser D \& Weary DM 2008. Parent-offspring resource allocation in domestic pigs. Behavioral Ecology and Sociobiology 62 309-319.

Dyck GW \& Swierstra EE 1987 Causes of piglet death from birth to weaning. Canadian Journal of Animal Science 67 543-547.

Edwards SA 1998 Nutrition of the rearing gilt and sow. In: Progress in Pig Science (Ed. by J.Wiseman, M.A.Varley \& J.P.Chatwick), pp. 361-383. Nottingham University Press, Nottingham.

Edwards SA 2002 Perinatal mortality in the pig: environmental or physiological solutions? Livestock Production Science 78 3-12.

Edwards SA \& Fraser D 1997 Housing systems for farrowing and lactation. The Pig Journal 39 77-89.

Edwards SA, Smith WJ, Fordyce C \& Macmenemy F 1994 An analysis of the causes of piglet mortality in a breeding herd kept outdoors. Veterinary Record 135 324-327.

English PR \& Edwards SA 1996 Management of the nursing sow and her litter. In: Pig Production: C10 (World Animal Science) (Ed. by M.R.Taverner \& A.C.Dunkin), pp. 113-140. Elsevier Health Sciences.

English PR \& Smith WJ 1975 Some causes of death in neonatal piglets. Veterinary Annual 15 95-104.

Fahmy MH \& Friend DW 1981 Factors influencing, and repeatability of the duration of farrowing in Yorkshire sows. Canadian Journal of Animal Science 61 17-22.

Forbes LS \& Mock DW 1998 Parental optimism and progeny choice: when is screening for offspring quality affordable? Journal of Theoretical Biology 192 3-14.

Foxcroft GR, Dixon WT, Novak S, Putman CT, Town SC \& Vinsky MDA 2006 The biological basis for prenatal programming of postnatal performance in pigs. Journal of Animal Science 84 E105-E112.

Fraser D \& Lin CS 1984 An attempt to estimate teat quality of sows by hand milking during farrowing. Canadian Journal of Animal Science 64 165-170.

Fraser D 1975 The 'teat order' of suckling pigs II. Fighting during suckling and the effects of clipping the eye teeth. Journal of Agricultural Science 84 393-399

Fraser D, Kramer DL, Pajor EA \& Weary DM 1995. Conflict and cooperation: sociobiological principles and the behaviour of pigs. Applied Animal Behaviour Science 44 139-157.

Gade S, Bennewitz J, Kirchner K, Looft H, Knap PW, Thaller G \& Kalm E 2007 Genetic parameters for maternal behaviour traits in sows. Livestock Science 114 31-41.

Gaskins HR \& Kelly KW 1995 Immunology and neonatal mortality. In: The Neonatal Pig: Develoment and Survival (Ed. by M.A.Varley), pp. 39-56. CAB International, Wallingford, UK.

Geisert RD \& Schmitt RAM 2002 Early embryonic survival in the pig: can it be improved? Journal of Animal Science 80 E54-E65.

Gluckmann PD \& Hanson MA 2004 Maternal constraints of fetal growth and its consequence. Seminars in Neonatology 9 419-425.

Grandinson K, Rydhmer L, Strandberg E \& Thodberg K 2003 Genetic analysis of on-farm tests of maternal behaviour in sows. Livestock Production Science $\mathbf{8 3}$ 141-151.

Grandinson K 2005 Genetic background of maternal behaviour and its relation to offspring survival. Livestock Production Science 93 43-50.

Head RH \& Williams IH 1992 Mammogenesis is influenced by pregnancy nutrition. In: Manipulating Pig Production III, p.33. Australian Pig Science Association.

Herpin P, Damon M \& LeDividich J 2002 Development of thermoregulation and neonatal survival in pigs. Livestock Production Science 78 25-45.

Herpin P \& LeDividich J 1995 Thermoregulation and the environment. In: The Neonatal Pig: Development and Survival (Ed. by M.A.Varley), pp. 57-95. CAB International, Wallingford, UK.

Herpin P, LeDividich J, Berthon D \& Hulin JC 1994 Assessment of thermoregulatory and postprandial thermogenesis over the first 24 hours after birth in pigs. Experimental Physiology 79 1011-1019.

Herpin P, LeDividich J \& Amaral N 1993 Effect of selection for lean tissue-growth on body-composition and physiological-state of the pig at birth. Journal of Animal Science 71 2645-2653.

Herpin P, LeDividich J, Hulin JC, Fillaut M, DeMarco 
F \& Bertin R 1996 Effect of the level of asphyxia during delivery on viability at birth and early postnatal vitality of newborn pigs. Journal of Animal Science 74 2067-2075.

Herskin MS, Jensen KH \& Thodberg K 1998 Influence of environmental stimuli on maternal behaviour related to bonding, reactivity and crushing of piglets in domestic sows. Applied Animal Behaviour Science 58 241-254.

Holyoake PK, Dial GD, Trigg T \& King VL 1995 Reducing pig mortality through supervision during the perinatal period. Journal of Animal Science 73 3543-3551.

Hrupka BJ, Leibbrandt VD, Crenshaw TD \& Benevenga NJ 2000 Effect of sensory stimuli on huddling behavior of pigs. Journal of Animal Science 78 592-596.

Huby M, Canario L, Tribout T, Caritez JC, Billon Y, Gogué J \& Bidanel JP 2003 Genetic correlations between litter size and weights, piglet weight variability and piglet survival from birth to weaning in Large White pigs. In Proceedings of the 54th Annual Meeting of the European Association for Animal Production Roma, Italy. Wageningen Pers, Wageningen, the Netherlands p362.

Jarvis S, D'Eath RB \& Fujita K 2005 Consistency of piglet crushing by sows. Animal Welfare 14 43-51.

Jarvis S, Lawrence AB, Mclean KA, Chirnside J, Deans LA \& Calvert SK 1998 The effect of environment on plasma cortisol and beta-endorphin in the parturient pig and the involvement of endogenous opioids. Animal Reproduction Science 52 139-151.

Jarvis S, Calvert SK, Stevenson J, van Leeuwen N \& Lawrence AB 2002 Pituitary-adrenal activation in pre-parturient pigs (Sus scrofa) is associated with behavioural restriction due to lack of space rather than nesting substrate. Animal Welfare 11 371-384.

Jarvis S, Reed BT, Lawrence AB, Calvert SK \& Stevenson J 2004 Peri-natal environmental effects on maternal behaviour, pituitary and adrenal activation, and the progress of parturition in the primiparous sow. Animal Welfare 13 171-181.

Jarvis S, Van der Vegt BJ, Lawrence AB, Mclean KA, Deans LA, Chirnside J \& Calvert SK 2001 The effect of parity and environmental restriction on behavioural and physiological responses of pre-parturient pigs. Applied Animal Behaviour Science 71 203-216.

Kerr JC \& Cameron ND 1995 Reproductive-performance of pigs selected for components of efficient lean growth. Animal Science 60 281-290.

Kim SW, Hurley WL, Han IK, Stein HH \& Easter RA 1999 Effect of nutrient intake on mammary gland growth in lactating sows. Journal of Animal Science 77 3304-3315.

Kirkden RD, Broom DM \& Andersen IL 2013 Piglet mortality: The impact of induction of farrowing using prostaglandins and oxytocin. Animal Reproduction Science. DOI: 10.1016/j.anireprosci.2013.02.009

Knol EF, Ducro BJ, van Arendonk JAM \& van der Lende T 2002a Direct, maternal and nurse sow genetic effects on farrowing-, pre-weaning- and total piglet survival. Livestock Production Science 73 153-164.
Knol EF, Leenhouwers JI \& van der Lende T 2002b Genetic aspects of piglet survival. Livestock Production Science 78 47-55.

Lawrence AB, Petherick JC, Mclean KA, Deans LA, Chirnside J, Vaughan A, Clutton E \& Terlouw EMC 1994 The effect of environment on behavior, plasmacortisol and prolactin in parturient sows. Applied Animal Behaviour Science 39 313-330.

Lay DCJr, Matteri RL, Carroll JA, Fangman TJ \& Safranski TJ 2002 Preweaning survival in swine. Journal of Animal Science $\mathbf{8 0}$ E74-E86.

Lee GJ, Ritchie M, Thomson M, Macdonald AA, Blasco A, Santacreu MA, Argente MJ \& Haley CS 1995 Uterine capacity and prenatal survival in Meishan and Large White-pigs. Animal Science 60 471-479.

Leenhouwers JI, Wissink P, van der Lende T, Paridaans H \& Knol EF 2003 Stillbirth in the pig in relation to genetic merit for farrowing survival. Journal of Animal Science 81 2419-2424

Leenhouwers JI, de Almeida CA, Knol EF \& van der Lende T 2001 Progress of farrowing and early postnatal pig behavior in relation to genetic merit for pig survival. Journal of Animal Science 79 1416-1422.

Leenhouwers JI, van der Lende T \& Knol EF 1999 Analysis of stillbirth in different lines of pig. Livestock Production Science 57 243-253.

Marchant JN, Broom DM \& Corning S 2001 The influence of sow behaviour on piglet mortality due to crushing in an open farrowing system. Animal Science 72 19-28.

Marchant JN, Rudd AR, Mendl MT, Broom DM, Meredith MJ, Corning S \& Simmins PH 2000 Timing and causes of piglet mortality in alternative and conventional farrowing systems. Veterinary Record 147 209-214.

Martineau GP, Vaillancourt JP \& Broes A 1995 Principal neonatal diseases. In: The Neonatal Pig: Development and Survival (Ed. by M.A.Varley), pp. 239-268. CAB International, Wallingford, UK.

Mclean KA, Lawrence AB, Petherick JC, Deans L, Chirnside J, Vaughan A, Nielsen BL \& Webb R 1998 Investigation of the relationship between farrowing environment, sex steroid concentrations and maternal aggression in gilts. Animal Reproduction Science $\mathbf{5 0}$ 95-109.

Mellor DJ \& Stafford KJ 2004 Animal welfare implications of neonatal mortality and morbidity in farm animals. Veterinary Journal 168 118-133.

Meunier-Salaün MC, Edwards SA \& Robert S 2001 Effect of dietary fibre on the behaviour and health of the restricted fed sow. Animal Feed Science Technology 90 53-69.

Milligan BN, Fraser D \& Kramer DL 2002 Within-litter birth weight variation in the domestic pig and its relation to pre-weaning survival, weight gain, and variation in weaning weights. Livestock Production Science 76 181-191.

Mock DW \& Forbes LS 1995 The evolution of parental optimism. Trends in Ecology \& Evolution 10 130-134.

Mota-Rojas D, Rosales AM, Trujillo ME, Orozco H, Ramirez R \& Alonso-Spilsbury M 2005 The effects of vetrabutin chlorhydrate and oxytocin on stillbirth rate 
and asphyxia in swine. Theriogenology 64 1889-1897.

Mota-Rojas D, Trujillo ME, Martinez J, Rosales AM, Orozco H, Ramirez R, Sumano H \& Alonso-Spilsbury M 2006 Comparative routes of oxytocin administration in crated farrowing sows and its effects on fetal and postnatal asphyxia. Animal Reproduction Science 92 123-143.

Mota-Rojas D, Martinez-Burnes J, Trujillo-Ortega ME, Alonso-Spilsbury M, Ramirez-Necoechea R \& Lopez A 2002 Effect of oxytocin treatment in sows on umbilical cord morphology, meconium staining, and neonatal mortality of piglets. American Journal of Veterinary Research 63 1571-1574.

Mount LE 1964 Radiant + convective heat loss from newborn pig. Journal of Physiology-London 173 96-113.

Mount LE 1967 The heat loss from new-born pigs to the floor. Research in Veterinary Science 8 175-186.

Mount LE 1968 The Climatic Physiology of the Pig. Edward Arnold, London.

Mouttotou N \& Green LE 1999 Incidence of foot and skin lesions in nursing piglets and their association with behavioural activities. Veterinary Record 145 160-165.

O'Dowd S, Hoste S, Mercer JT, Fowler VR \& Edwards SA 1997 Nutritional modification of body composition and the consequences for reproductive performance and longevity in genetically lean sows. Livestock Production Science 52 155-165.

Oliviero C, Heinonen M, Valros A, Halli O \& Peltoniemi OAT 2006 Duration of farrowing is longer in sows housed in farrowing crates than in pens. Reproduction in Domestic Animals 41 367-367.

Pedersen LJ, Berg P, Jorgensen G \& Andersen IL 2011b Neonatal piglet traits of importance for survival in crates and indoor pens. Journal of Animal Science 89 1207-1218.

Pedersen LJ, Jorgensen E, Heiskanen T \& Damm BI 2006 Early piglet mortality in loose-housed sows related to sow and piglet behaviour and to the progress of parturition. Applied Animal Behaviour Science 96 215-232.

Pedersen JH, Moustsen VA \& Hansen CF 2011a Physical characteristics of surviving piglets born in a loose farrowing system. In Manipulating Pig Production XIII Proceedings of the $13^{\text {th }}$ biennial conference of the Australasian Pig Association (APSA), Adelaide, Australia p.245.

Pedersen ML, Moustsen VA, Nielsen MBF and Kristensen AR 2011c Improved udder access prolongs duration of milk letdown and increases piglet weight gain. Livestock Science 140 253-261.

Pope WF 1994 Embryonic mortality in swine. In: Embryonic Mortality in Domestic Species (Ed. by M.T.Zavy), pp. 53-78. CRC Press, Boca Raton, FL.

Quesnel H, Farmer C \& Devillers N 2012 Colostrum intake: influence on piglet performance and factors of variation. Livestock Science 146 105-114.

Quiniou N, Dagorn J \& Gaudre D 2002 Variation of piglets' birth weight and consequences on subsequent performance. Livestock Production Science 78 63-70.

Randall GC 1972a. Observations on parturition in the sow. I. Factors associated with the delivery of the piglets and their subsequent behaviour. Veterinary Record 90 178-182.

Randall GC 1972b Observations on parturition in the sow. II. Factors influencing stillbirth and perinatal mortality. Veterinary Record 90 183-186.

Randall GCB \& Penny RHG 1970 Stillbirth in the pig: an analysis of the breeding records of five herds. British Veterinary Journal 126 593-603.

Rees S, Mallard C, Breen S, Stringer M, Cock M \& Harding R 1998 Fetal brain injury following prolonged hypoxemia and placental insufficiency: a review. Comparative Biochemistry and Physiology - Part A: Molecular \& Integrative Physiology 119 653-660.

Riart GR, Edwards SA \& English PR 2000 Assessment of hypothermia in outdoor newborn piglets and comparison with an indoor system. Proceedings of the British Society of Animal Science p.139.

Robertson JB, Laird R, Forsyth JKS, Thomson JM \& Walker-Love T 1966 A comparison of two indoor farrowing systems for sows. Animal Production 871.

Roehe R 1999 Genetic determination of individual birth weight and its association with sow productivity using Bayesian analyses. Journal of Animal Science 77 330-343.

Roehe R \& Kalm E 2000 Estimation of genetic and environmental risk factors associated with pre-weaning mortality in piglets using generalized linear mixed models. Animal Science 70 227-240.

Roehe R, Shrestha NP, Mekkawy W, Baxter EM, Knap PW, Smurthwaite KM, Jarvis, S, Lawrence AB \& Edwards SA 2009 Genetic analysis of piglet survival and individual birth weight of first generation data of a selection experiment for piglet survival under outdoor conditions. Livestock Science 121 173-181.

Roehe R, Shrestha NP, Mekkawy W, Baxter EM, Knap PW, Smurthwaite KM, Jarvis, S, Lawrence AB \& Edwards SA 2010 Genetic parameters of piglet survival and birth weight from a two-generation crossbreeding experiment under outdoor conditions designed to disentangle direct and maternal effects. Journal of Animal Science 88 1276-1285.

Rooke JA \& Bland IM 2002 The acquisition of passive immunity in the new-born piglet. Livestock Production Science 78 13-23.

Rooke JA, Sinclair AG, Edwards SA, Cordoba R, Pkiyach S, Penny PC, Penny P, Finch AM \& Horgan GW 2001 The effect of feeding salmon oil to sows throughout pregnancy on pre-weaning mortality of piglets. Animal Science 73 489-500.

Rootwelt V, Reksen O, Farstad W \& Framstad T 2012 Associations between intrapartum death and piglet, placental, and umbilical characteristics. Journal of Animal Science 90 4289-4296.

Rutherford KMD, Baxter EM, D'Eath RB, Turner SP, Arnott G, Roehe R, Ask B, Sandøe P, Mousten VA, Thorup F, Edwards SA, Berg P \& Lawrence AB 2013 The welfare implications of large litter size in the domestic pig I: biological factors. Animal Welfare 22 199-218. doi: 10.7120/09627286.22.2.199 
Rydhmer L 2000 Genetics of sow reproduction, including puberty, oestrus, pregnancy, farrowing and lactation. Livestock Production Science 66 1-12.

Schmid H 1994 Ethological design of a practicable farrowing pen. Applied Animal Behaviour Science 40 94-95.

Stanton HC, Brown LJ \& Mueller RL 1973 Interrelationships between maternal and neonatal factors and thermoregulation in fasted neonatal swine (Sus domesticus). Comparative Biochemistry and Physiology Part A: Physiology 44 97-105.

Su G, Lund MS \& Sorensen D 2007 Selection for litter size at day five to improve litter size at weaning and piglet survival rate. Journal of Animal Science 85 1385-1392.

Thodberg K, Jensen KH \& Herskin MS 2002 Nest building and farrowing in sows: relation to the reaction pattern during stress, farrowing environment and experience. Applied Animal Behaviour Science 77 21-42.

Thodberg K, Jensen KH, Herskin MS \& Jorgensen E 1999 Influence of environmental stimuli on nest building and farrowing behaviour in domestic sows. Applied Animal Behaviour Science 63 131-144.

Trujillo-Ortega ME, Mota-Rojas D, Olmos-Hernandez A, Alonso-Spilsbury M, Gonzalez $M$, Orozco $H$, Ramirez-Necoechea R \& Nava-Ocampo A 2007 A study of piglets born by spontaneous parturition under uncontrolled conditions: could this be a naturalistic model for the study of intrapartum asphyxia? Acta Biomedica 78 29-35.

Vaillancourt J-P, Stein TE, Marsh WE, Leman AD \& Dial GD 1990 Validation of producer-recorded causes of preweaning mortality in swine. Preventive Veterinary Medicine 10 119-130.

Vallet JL, Leymaster KA \& Christenson RK 2002 The influence of uterine function on embryonic and fetal survival. Journal of Animal Science 80 E115-E125.

Vallet JL, Miles JR, Brown-Brandl TM \& Nienaber JA 2010 Proportion of litter farrowed, litter size, and progesterone and estradiol effects on piglet birth intervals and stillbirths. Animal Reproduction Science 119 68-75.

Van den Brand $\mathbf{H}$, van Enckewort LCM, van der Hoeven EM \& Kemp B 2009 Effects of dextrose plus lactose in the sows diet on subsequent reproductive and within litter birth weight variation. Reproduction in Domestic Animals 44 884-888 van der Lende T, Knol EF \& Leenhouwers JI 2001 Prenatal development as a predisposing factor for perinatal losses in pigs. Reproduction Supplement 58 247-261.

van Dijk AJ, van Loon JPAM, Taverne MAM \& Jonker FH 2008 Umbilical cord clamping in term piglets: A useful model to study perinatal asphyxia? Theriogenology 70 662-674.

van Dijk AJ, van Rens BTTM, van der Lende T \& Taverne MAM 2005 Factors affecting duration of the expulsive stage of parturition and piglet birth intervals in sows with uncomplicated, spontaneous farrowings. Theriogenology 64 1573-1590.

van Kempen T 2007 Sports supplements to facilitate parturition and reduce perinatal mortality. In $\mathrm{P}$ Garnsworthy and J Wiseman (eds). Recent Advances in Animal Nutrition. Nottingham University Press, Nottingham, UK.

van Rens BTTM, de Koning G, Bergsma R \& van der Lende T 2005 Preweaning piglet mortality in relation to placental efficiency. Journal of Animal Science $\mathbf{8 3}$ 144-151.

van Rens BTTM \& van der Lende T 2004 Parturition in gilts: duration of farrowing, birth intervals and placenta expulsion in relation to maternal, piglet and placental traits. Theriogenology 62 331-352.

Vanderhaeghe C, Dewulf J, Ribbens S, deKruif A \& Maes D 2010 A cross-sectional study to collect risk factors associated with stillbirths in pig herds. Animal Reproduction Science 118 62-68.

Weary DM, Pajor EA, Thompson BK \& Fraser D 1996 Risky behaviour by piglets: A trade off between feeding and risk of mortality by maternal crushing? Animal Behaviour 51 619-624.

Wechsler B \& Weber R 2007 Loose farrowing systems: challenges and solutions. Animal Welfare 16 295-307.

Wilson ME, Biensen NJ, Youngs CR \& Ford SP 1998 Development of Meishan and Yorkshire littermate conceptuses in either a Meishan or Yorkshire uterine environment to day 90 of gestation and to term. Biology of Reproduction 58 905-910.

Wu G, Bazer FW, Cudd TA, Meininger CJ \& Spencer TE 2004 Maternal nutrition and fetal development. Journal of Nutrition 134 2169-2172.

Zaleski HM \& Hacker RR 1993 Comparison of viability scoring and blood-gas analysis as measures of piglet viability. Canadian Journal of Animal Science $\mathbf{7 3}$ 649-653. 
